\title{
Review
}

\section{Cellular Physiolosy

\section{Methods Employed for Induction and Analysis of Experimental Myocardial Infarction in Mice}

\author{
Oliver Borst ${ }^{1,2, *}$, Carmen Ochmann ${ }^{1, *}$, Tanja Schönberger ${ }^{1}$, Christoph \\ Jacoby $^{3}$, Konstantinos Stellos ${ }^{1}$, Peter Seizer ${ }^{1}$, Ulrich Flögel $^{3}$, Florian \\ Lang $^{2}$ and Meinrad Gawaz ${ }^{1}$
}

${ }^{1}$ Departmernt of Cardiology and Cardiovascular Medicine, University Hospital Tübingen, Tübingen, ${ }^{2}$ Department of Physiology, Eberhard Karls University Tübingen, ${ }^{3}$ Department of Cardiovascular Physiology, Heinrich Heine University Düsseldorf, Düsseldorf, *Both authors contributed equally to this work

\section{Key Words}

Mice - Myocardial infarction - Reperfusion - Tissue remodeling $\cdot$ Anesthesia $\cdot$ Analgesia $\cdot$ Artery ligation - Coronary occlusion - Echocardiography • Magnetic resonance imaging $\bullet$ Infarct size

\begin{abstract}
Myocardial ischemia und subsequent reperfusion is followed by a complex sequence of pathophysiological responses involving inflammatory cell infiltration and cytokine release as well as postinfarction wound healing and myocardial tissue remodeling. With the development of gene targeted mice the contribution of individual gene products to the pathophysiology of myocardial ischemia and reperfusion can be defined leading to an increasing interest in the widelyused mouse model of myocardial infarction. This methological paper describes in detail the required equipment, surgical instruments, drugs and additional material, the methods of anesthesia and analgesia, the procedures involved in preparation of the animal, tracheotomy, intubation, thoracotomy, occlusion of the left descending artery, removal of the heart,
\end{abstract}

\section{KARGER}

Fax +41613061234

E-Mail karger@karger.ch

www.karger.com
(C) 2011 S. Karger AG, Basel

1015-8987/11/0281-0001\$38.00/0

Accessible online at:

www.karger.com/cpb determination of infarct size, analysis of cardiac functional parameters with echocardiography and magnetic resonance imaging (MRI) as well as determination of the morphological consequences utilizing gelatin zymography, histology and immunohistochemistry.

Copyright @ 2011 S. Karger AG, Basel

\section{Introduction}

Myocardial ischemia followed by reperfusion triggers a complex sequence of pathophysiological responses involving inflammation, new tissue formation and postinfarction tissue remodeling [1-3]. This dynamic pathological process includes adhesion and migration of inflammatory cells, release of cytokines and matrix metalloproteinases as well as extracellular matrix degradation and subsequent myocardial reparation with increased new collagen synthesis [4-6].

The mouse model of myocardial infarction (MI) was first published 1995 by Michael et al. [7] for investigating

Meinrad Gawaz, MD

Medizinische Klinik, Abteilung III (Cardiology), Universitätsklinikum Tübingen Otfried-Müller Str. 10, 72076 Tübingen (Germany)

Tel. +49-7071-29-83688, Fax +49-7071-29-5040

E-Mailmeinrad.gawaz@med.uni-tuebingen.de 
pathophysiological mechanisms in myocardial ischemia. For this purpose it is essential to develop a standardized technique for ligation of the left anterior descending artery (LAD) to permit infarcts of uniform size.

In this methodological paper the techniques required for anesthesia, surgical manipulation, coronary occlusion, reperfusion and postoperative management of the mouse are described. Furthermore, we address echocardiography and magnetic resonance imaging (MRI) as non-invasive additional examination methods and several ex vivo evaluation methods.

\section{Equipment, surgical instruments, drugs and additional material}

Since all surgical procedures are carried out with a microscope, a stereo zoom microscope and a fiber optic cold light source are essential. The required surgical instruments are shown in Fig. 1.

For preparation of the mouse a shaving machine, depilatory cream, eye ointment and polyvinylpyrrolidone iodine (povidone-iodine) for disinfection are needed.

To perform the anesthesia several drugs (Table 1), an anesthesia machine, a rodent ventilator (e.g. HSEHA MiniVent ventilator for mice, Harvard Apparatus, USA) and a tracheotomy cannula (1.3 mm OD, $1 \mathrm{~mm}$ ID) are necessary. To maintain the body temperature a heating pad and a rectal probe connected to a temperature controller are used. As suture material braided silk suture 6-0 (e.g. Mersilk ${ }^{\circledR}$, Ethicon); monofilament, synthetic, nonabsorbable sterile suture 6-0 and 7-0 (e.g. Prolene ${ }^{\circledR}$, Ethicon) and synthetic absorbable sterile suture 6-0 and 8-0 (e.g. Vicryl ${ }^{\circledR}$, Ethicon) are appropriate. Chemicals required are listed in Table 1.

\section{Anesthesia and analgesia}

Complete antagonisation of the anesthesia after surgery is beneficial for circulation. The mice are anesthetized by an intraperitoneal injection of a solution of midazolame ( $5 \mathrm{mg} / \mathrm{kg}$ body weight), medetomidine $(0.5$ $\mathrm{mg} / \mathrm{kg}$ body weight) and fentanyl $(0.05 \mathrm{mg} / \mathrm{kg}$ body weight) [8]. Later, the anesthesia is maintained by inhalation of isoflurane $\left(0.7-1.5 \mathrm{Vol} . \%\right.$ in $\left.\mathrm{O}_{2}\right)$.

As alternative anesthesia a combination of ketamine $(100-150 \mathrm{mg} / \mathrm{kg}$ body weight $)$ and medetomidine $(0.25$ $\mathrm{mg} / \mathrm{kg}$ body weight) is possible [8].

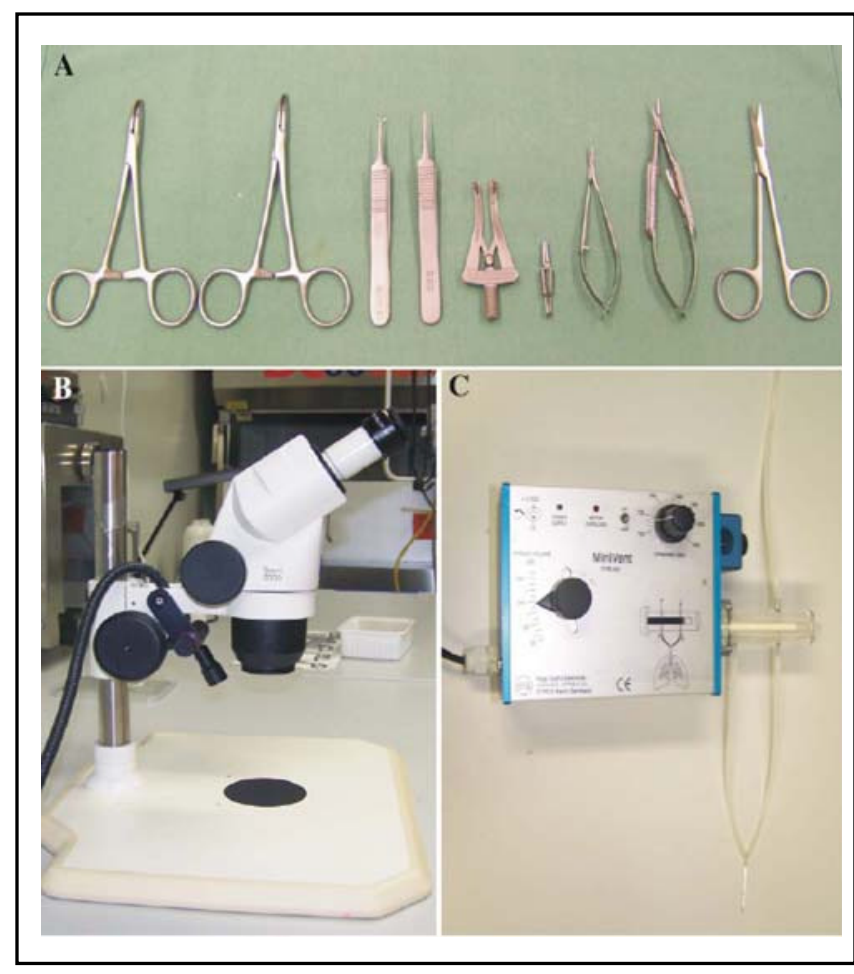

Fig. 1. Required surgical instruments and some equipment. (A) Instruments from the left to the right: 2 clamps (e.g. Halsted Mosquito hemostats), angled forceps, straight forceps, rip retractor, small bulldog clamp, micro scissor, needle holder, surgical scissor. (B) All surgical procedures are carried out with a stereo zoom microscope as well as a fiber optic cold light source. (C) Artificial ventilation is performed with a rodent ventilator for mice.

\begin{tabular}{l}
\hline Chemicals \\
\hline Medetomidine \\
Fentanyl \\
Midazolame \\
Isoflurane \\
Buprenorphine \\
Atipamezole \\
Flumazenil \\
$0.9 \%$ sodium chloride solution \\
Ringer's solution \\
$5 \%$ glucose solution \\
1 M potassium chloride solution $(\mathrm{KCl})$ \\
$0.5 \%$ Evans Blue \\
$1 \%$ TTC $(2,3,5$,-triphenyltetrazoliumchloride) \\
$4 \%$ formaldehyde \\
Tissue-Tec $\AA$ O.C.T.TM Compound
\end{tabular}

Table 1. Chemicals required for the induction and analysis of experimental myocardial infarction

Borst/Ochmann/Schönberger/Jacoby/Stellos/Seizer/Flögel/Lang/ Gawaz 
For analgesia an opiod analgeticum should be used, for example buprenorphine $(0.05-0.1 \mathrm{mg} / \mathrm{kg}$ body weight, s.c., every 8 hours); the first injection should be given in the recovery phase.

\section{Preparation and bedding}

For protecting the cornea eye ointment is applied. The thoracic wall of the narcotized mouse is shaved on the left side. This area as well as the chin is treated with depilatory cream (Fig. 2). These areas are cleaned and disinfected with povidone-iodine.

Thereafter the mouse is fixed in supine position with extremities taped on the operating table. For subsequent tracheotomy hyperextension of the neck is helpful, for example by positioning a cannula sheath under the neck. Furthermore, the right side of the mouse must be marginally uplifted.

To maintain the body temperature at $37 \pm 1{ }^{\circ} \mathrm{C}$ a controllable heating pad and a thermometer with a rectal probe are used.

\section{Tracheotomy and intubation}

A midline cervical skin incision is made by lifting the skin with straight forceps and cutting with the microscissor. The salivary glands are separated atraumatically. After gentle separation of the muscles (M. sternohyoideus, M. sternothyroideus) overlying the trachea they are fixed aside with sutures (Prolene $\left.{ }^{\circledR}, 6-0\right)$ and clamps. Now the trachea is visible. A cut between the fourth and fifth tracheal cartilage is made and a suture (Prolene ${ }^{\circledR}, 7-0$ ) is attached on the posterior tracheal cartilage. A bulldog clamp is fixed at the suture. This the suture can be used to facilitate the intubation (Fig. 3). Subsequently, the tracheotomy cannula is connected to a rodent ventilator via a tube. Artificial ventilation ( 120 strokes $/ \mathrm{min}, 180 \mu \mathrm{l}$ volume, $0.8 \mathrm{l} / \mathrm{min}$ oxygen flow) is provided throughout the procedure.

\section{Thoracotomy and left descending artery (LAD) occlusion}

To perform a thoracotomy at the left side the mouse is relocated on its right side. The skin is incised and the subcutaneous tissue is dissected free, the ventral serrated muscle of thorax and the intercostal muscles are

Experimental Myocardial Infarction in Mice
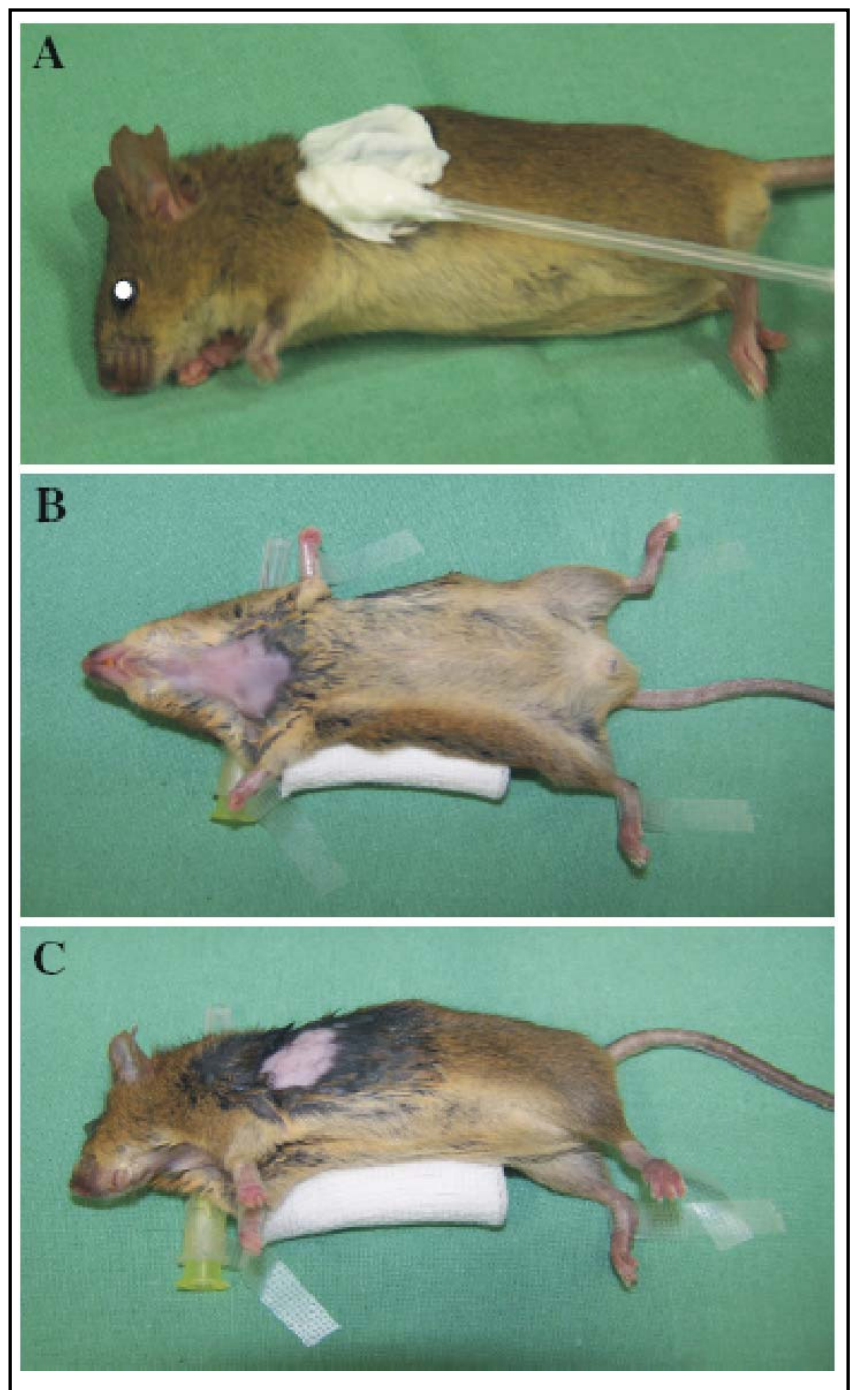

Fig. 2. Preparation and bedding of the mouse. (A) After anesthesia and application of eye ointment the thoracic wall as well as the chin are shaved and treated with depilatory cream. Thereafter both areas are cleaned and disinfected. (B) Bedding for tracheotomy: The mouse is fixed in the supine position with extremities taped on the operating table. A cannula sheath under the neck causes a hyperextension and facilitates the intubation. (C) Bedding for thoracotomy: The mouse is relocated whereas the right side must be marginally uplifted.

transected. The thorax is incised in the third intercostal space (Fig. 4). The opening is widened with a rip retractor. The lung is displaced with the help of Ethikeil ${ }^{\circledR}$ (Ethicon) to visualize the left auricle, at whose tip the left anterior descending artery takes course toward the apex of the heart. Before occlusion it is essential to open carefully the pericardium.

Cell Physiol Biochem 2011;28:01-12 
Fig. 3. Tracheotomy and intubation. (A) A midline cervical skin incision is made and the salivary glands as well as the muscles overlying the trachea are gently separated. $(B, C)$ The muscles are fixed aside with sutures and clamps. Thereby the trachea is visible. (D, E) A cut is made between the fourth and fifth tracheal cartilage. (E, F) Intubation is facilitated by attaching a suture on the posterior tracheal cartilage on which a small bulldog clamp is fixed.

Fig. 4. Thoracotomy. (A) The mouse is relocated on its right side and the skin is incised. (B, C) The subcutaneous tissue is dissected free. (D) The ventral serrated muscle of thorax is transected. (E) The intercostal muscles are incised in the third intercostal space. (F) The opening is widened with a rip retractor.
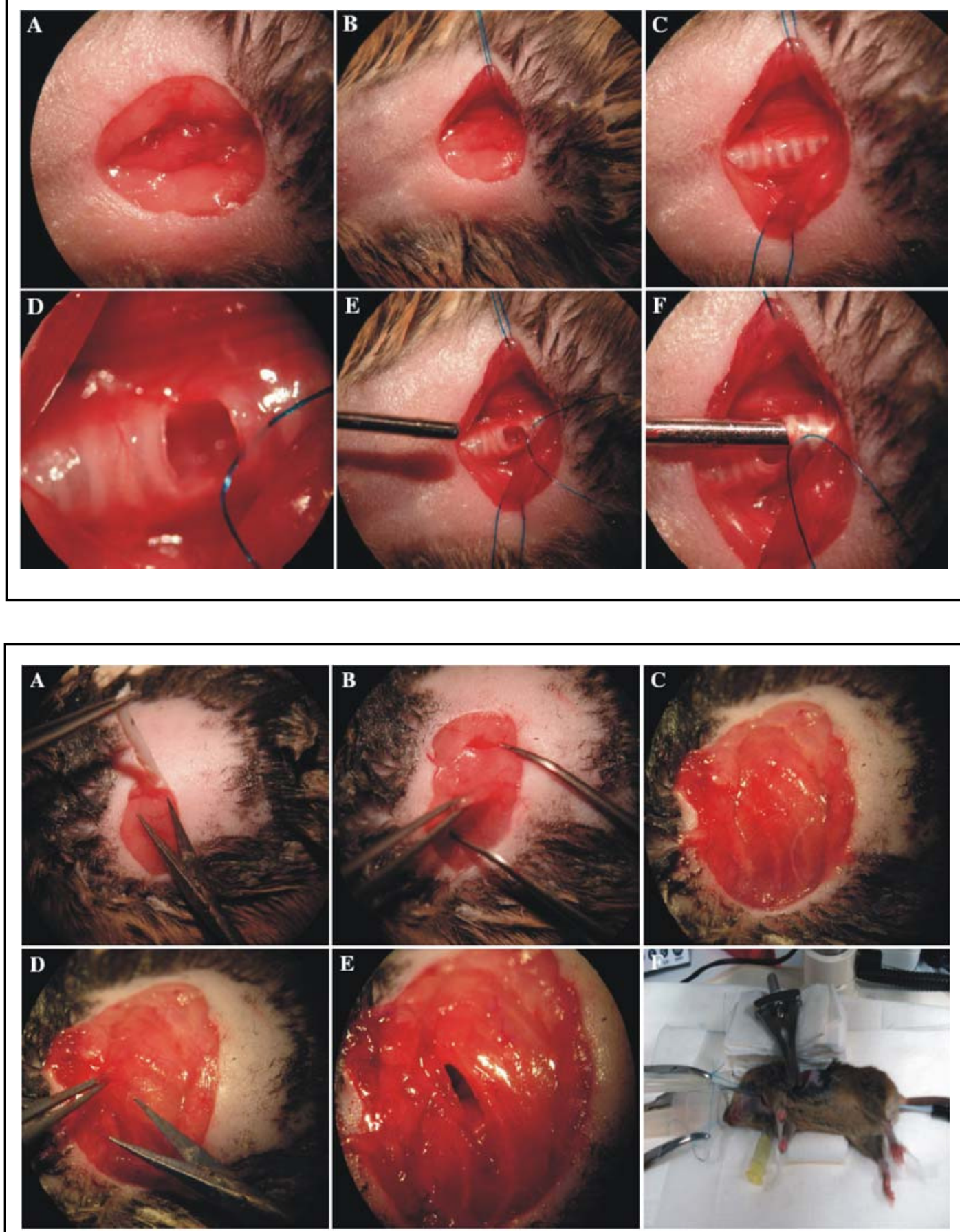

There are two anatomical patterns how the left anterior descending artery (LAD) takes course: first, there is a major singular LAD. Second, there exists a major bifurcation of the artery, which is close to the left auricle [7]. Branches of the mouse LAD penetrate the myocardium close to their origin [9]. Silk 6-0 is used to occlude the LAD just proximal to the site where the artery splits into two smaller branches or alternatively at the level of the tip of the auricle [10].

To later allow the reestablishment of blood flow, occlusion is produced by placing a $3 \mathrm{~mm}$ long piece of polyethylene tubing (Portex ${ }^{\circledR}$, Smiths Medical, $0.28 \mathrm{~mm}$ ID, $0.61 \mathrm{~mm} \mathrm{OD}$ ) on the artery and fixing it in place with a ligature (Fig. 5). It is essential to contract the knot by

Borst/Ochmann/Schönberger/Jacoby/Stellos/Seizer/Flögel/Lang/ Gawaz 
Fig. 5. Occlusion of the (left descending artery) LAD. (A) By widening the intercostal space the left side of the heart and the lung become apparent. (B) After opening the pericardium the left auricle is visible $(\downarrow)$ at whose tip the LAD $(\downarrow)$ takes course towards the apex. $(C, D)$ The LAD is occluded at the level of the tip of the left auricle. (E) A loose snare is formed. (F) Furthermore a piece of polyethylene tubing is placed on the artery to later allow the reestablishment of blood flow.

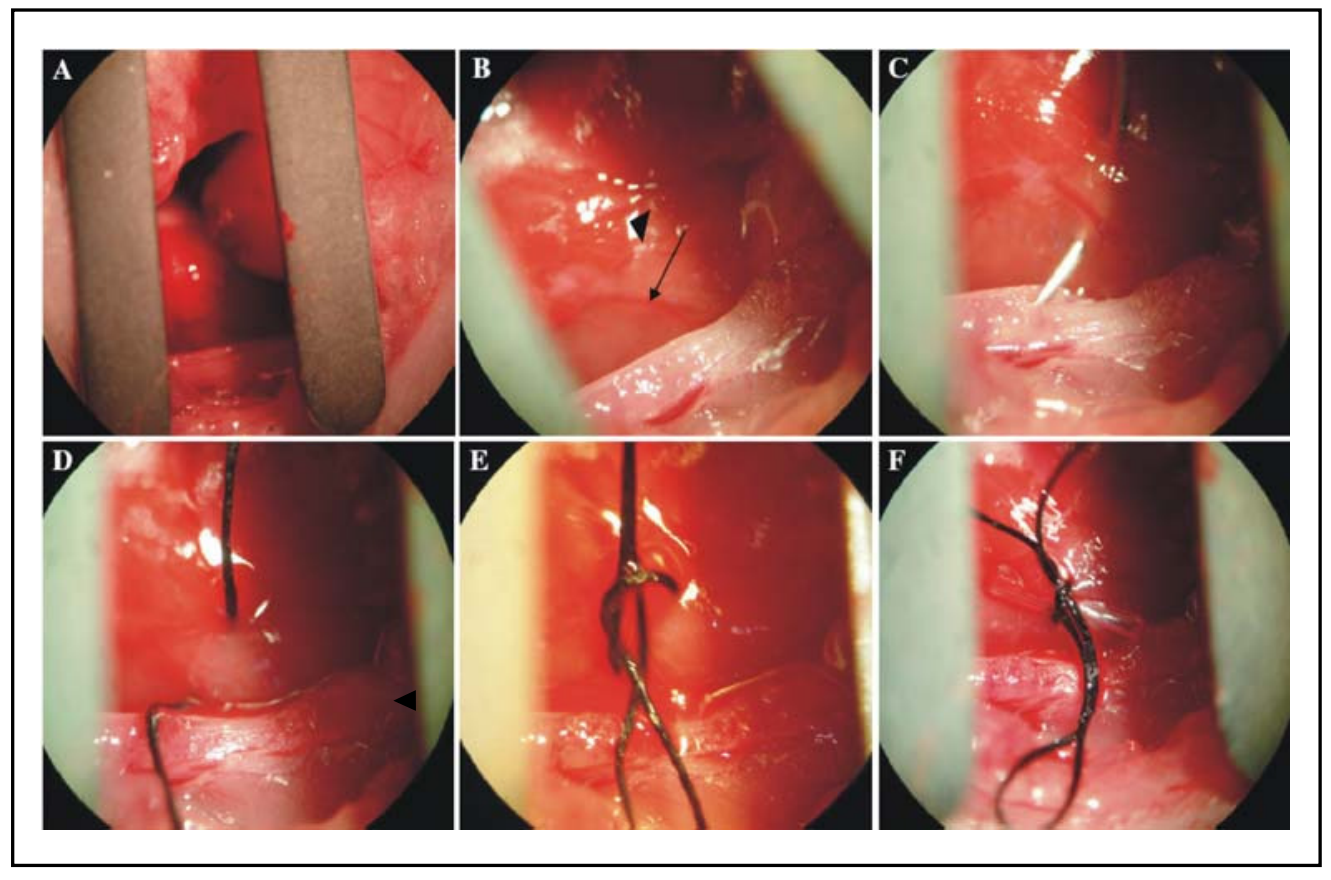

Fig. 6. Wound closure. (A) After removing the rip retractor the silk suture thread which retains in the myocardial tissue, is deposited outside the thorax. The intercostal muscles and the peritoneum are closed with interrupted suture. (B) The silk suture thread is placed onto this suture. The ventral serrated muscle of thorax, fascia and subcutaneous tissue are closed continuously. (C) The skin is closed in interrupted sutures. (D, E) After extubation the trachea is closed with a single knot. (F) The holding sutures are removed and the skin is closed in interrupted sutures.
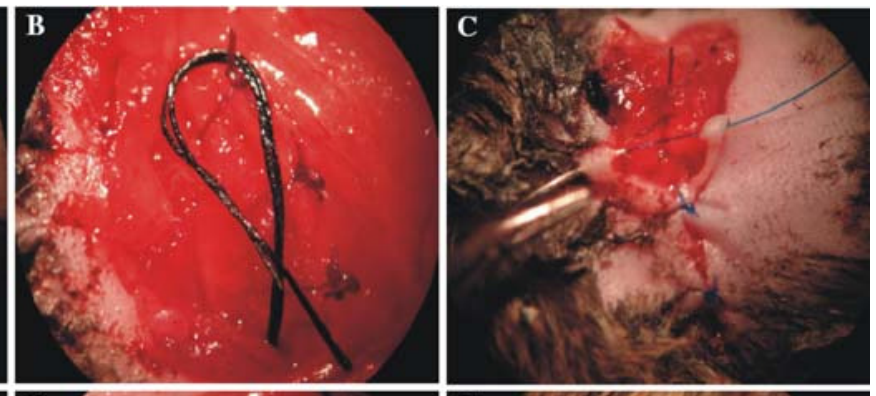
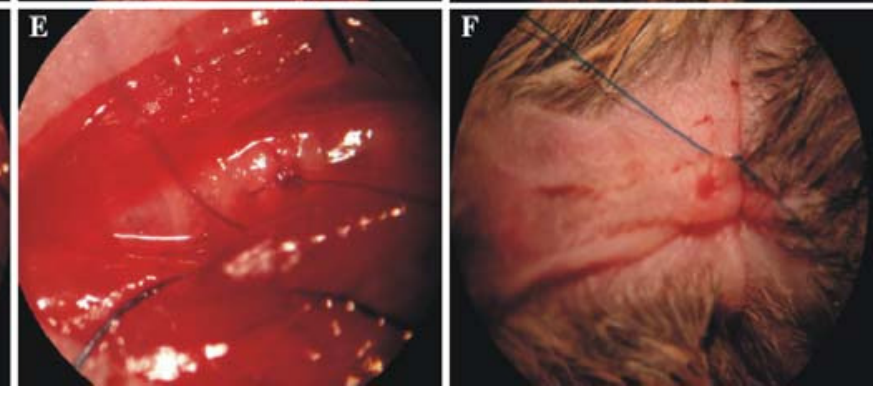

forming a loose snare. The discoloration of the left ventricle wall indicates the interruption of the coronary flow and verifies the successful myocardial infarction. The occlusion of the LAD must be retained for a welldefined period to achieve presentable infarct sizes. Ischemia is maintained 30 minutes. After this period the ischemia is terminated by removing the polyethylene tubing

Experimental Myocardial Infarction in Mice and opening the knot. The suture should be left in the myocardial tissue for the Evans Blue staining, which is performed before removing the heart. Reperfusion can be identified by visual inspection. The rip retractor is removed and the silk 6-0 suture thread is deposited outside the thorax. The intercostal space and the pleura are closed with interrupted suture by using Vicryl® 6-0. The silk 
Fig. 7. Evans Blue staining. (A) The skin of the anesthetized and intubated mouse is opened at the place where the xiphoid process of the sternum can be found. (B) Furthermore the pericardium is transected. (C) The diaphragm is cut through. The thorax is opened by cutting the rips on the right side of the sternum, shifting it to the left and fixating it with a clamp. (D) The silk suture is located and pulled out the muscle. (E) The left anterior descending artery ligature is retied. (F, G, H) $0.5 \mathrm{ml}$ Evans Blue dye is injected into the left cavity. The circulating dye is uniformly distributed except in the heart region supplied by the occluded coronary artery. (I) Successful dye injection can be verified by visualization of blue stained capillaries and organs.

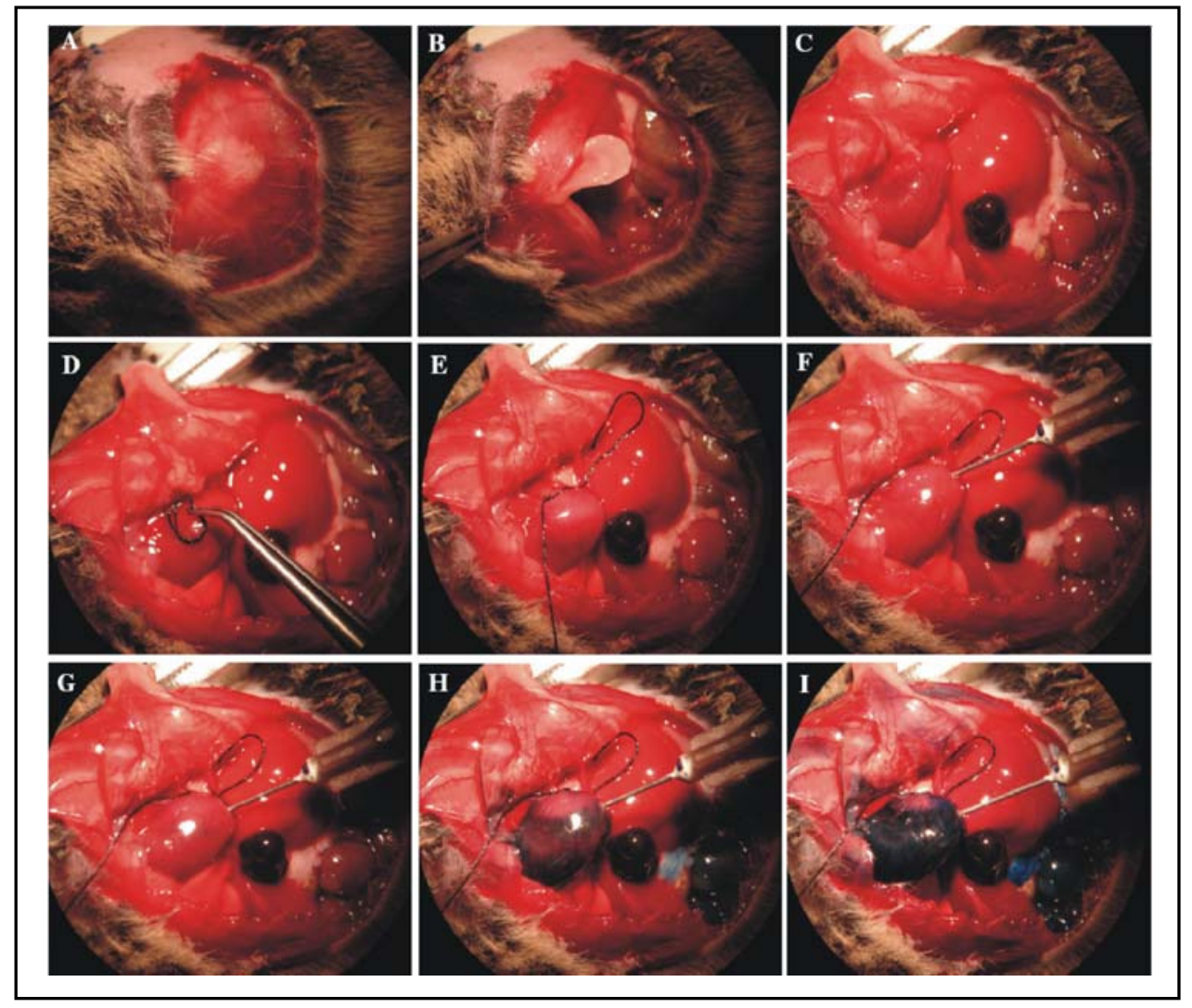

Fig. 8. Determination of infarct size. (A) The heart is removed and cleaned with sodium chloride solution. Now the whole heart is stained blue except the area at risk which was not affected by the occlusion. The heart is embedded in Tissue Tec ${ }^{\circledR}$ and frozen at -20 ${ }^{\circ} \mathrm{C}$. (B) Afterwards it is sectioned transversely with a scalpel into 5 slices. The sections are cleaned again and incubated in $1 \%$ TTC for 10 minutes. (C) The slices are fixed in $4 \%$ formaldehyde for at least 2 hours. Now the infarcted area appears pale white and the viable myocardium stains red. The region which was not affected by the occlusion is identified by the blue-staining. (D) After photographing the tissue sections the different regions can be determined by quantitative morphometric planimetry.

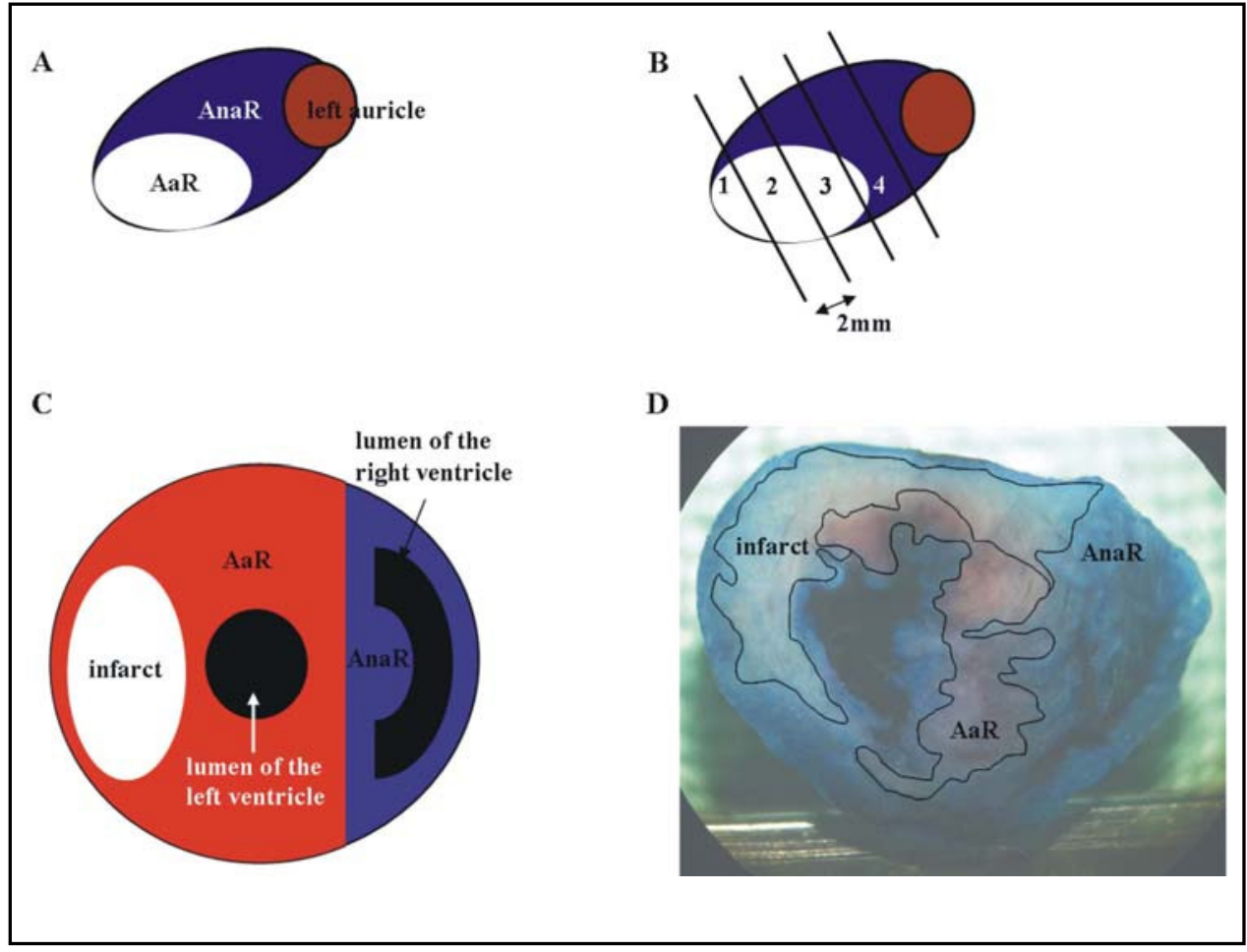

suture is placed onto this suture. Afterwards, the ventral serrated muscle of thorax, fascia and subcutaneous tissue are closed with continuous 6-0 Prolene ${ }^{\circledR}$ sutures. In contrast, the skin is closed with interrupted sutures (Fig. $6 \mathrm{~A}-\mathrm{C}$ ). The isoflurane supply is decreased whereas the oxygen flow must be raised. Now buprenorphine 
Fig. 9. Evaluation of cardiac function by using 2dimensional echocardiography. (A) End-systolic cavity areas from left ventricle long-axis and short-axis view in untreated mice. (B) Endsystolic cavity areas from left ventricle long-axis and shortaxis views 7 days after myocardial infarction. (C) Fractional area change can be calculated by manually tracing the endocardial border of the left ventricle in end-systolic and end-diastolic points of time.

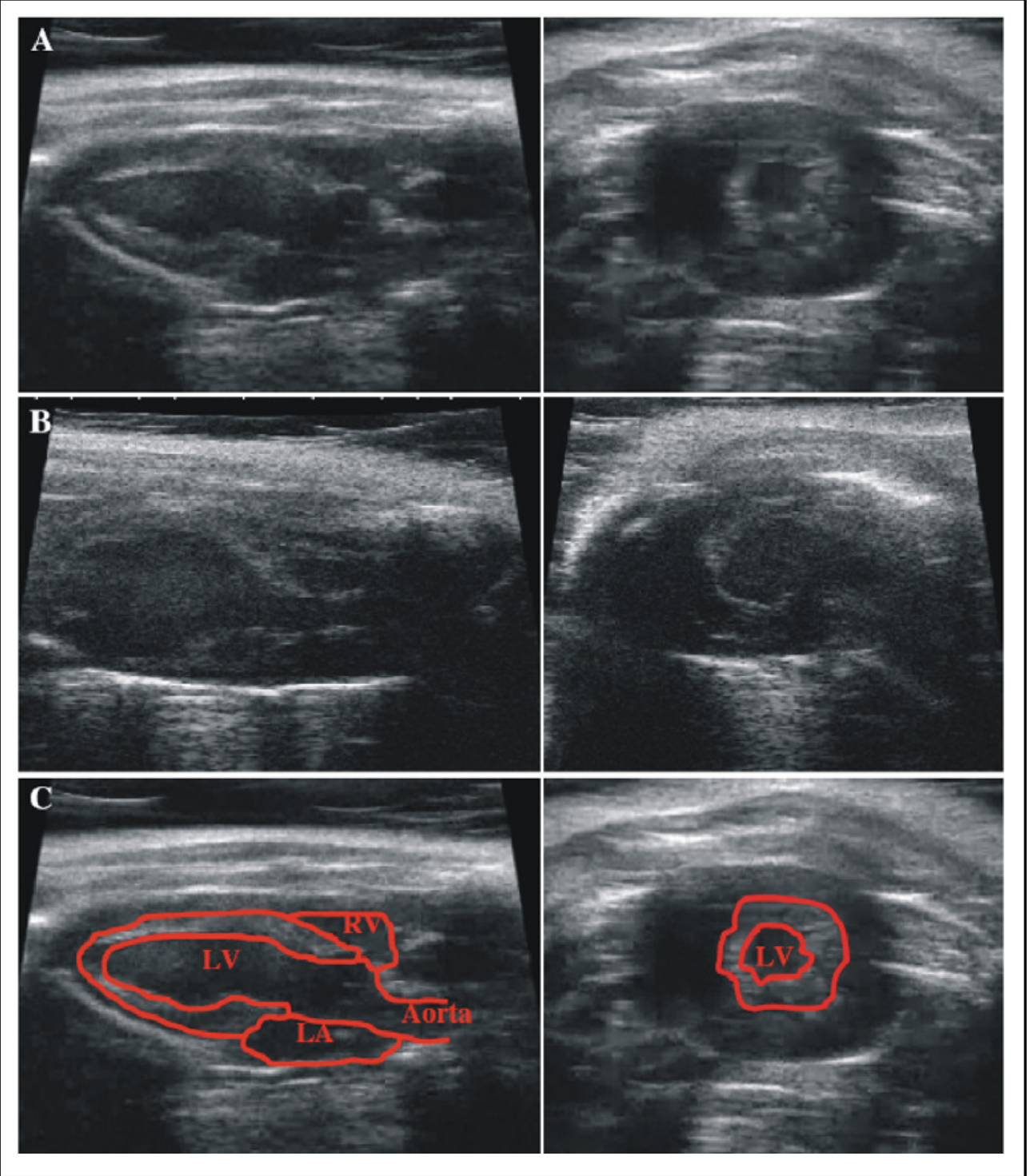

should be administered because the analgetic effect starts not until 20-30 min after application.

For extubation the mouse is relocated in the supine position. As soon as the mouse breaths autonomously the tracheotomy cannula is taken off from the trachea. The latter is closed with a single Vicryl ${ }^{\circledR}$ 8-0 knot. The holding sutures are removed and the skin is closed with Prolene ${ }^{\circledR}$ 6-0 in interrupted sutures (Fig. 6 $\mathrm{D}-\mathrm{F})$. To support the circulation the mouse is medicated with Ringer's solution and $5 \%$ glucose solution by a subcutaneous injection. To antagonize the anesthesia a mixture consisting of atipamezole $(2.5 \mathrm{mg} / \mathrm{kg}$ body weight $)$ and flumazenil $(0.5 \mathrm{mg} / \mathrm{kg}$ body weight $)$ is given subcutaneously. The mouse is allowed to recover from the surgery under a heating lamp. The injection of buprenorphine is repeated in an interval of 8 hours for 3 days.

Experimental Myocardial Infarction in Mice

\section{Removal of the heart and determination of infarct size}

At the end of the reperfusion period the mouse is anesthetized again. The intubation is carried out as already described. The isoflurane supply is raised to $2 \mathrm{Vol}$. \%.

The abdomen is cut open at the place where the xiphoid process of sternum can be found. Furthermore the diaphragm is cut. The thorax is opened up by cutting the rips on the right side of the sternum, shifting it to the left and fixating it with a clamp. The silk suture is located and the left anterior descending artery ligature is retied. $0.5 \mathrm{ml}$ of $5 \%$ Evans Blue dye is injected into the left ventricular cavity (Fig. 7). The circulating dye is uniformly distributed except in the heart region supplied by the occluded coronary artery. This domain illustrates the area at risk, which is affected by the ischemia. The mouse is

Cell Physiol Biochem 2011;28:01-12 
Fig. 10. Evaluation of cardiac function by magnetic resonance imaging (MRI). Short axis slices of a mouse heart before (A) as well as 1 (B), 2 (C) and 3 (D) weeks after ligation of the LAD. Ventricular wall becomes thin in the region of the ligated LAD.
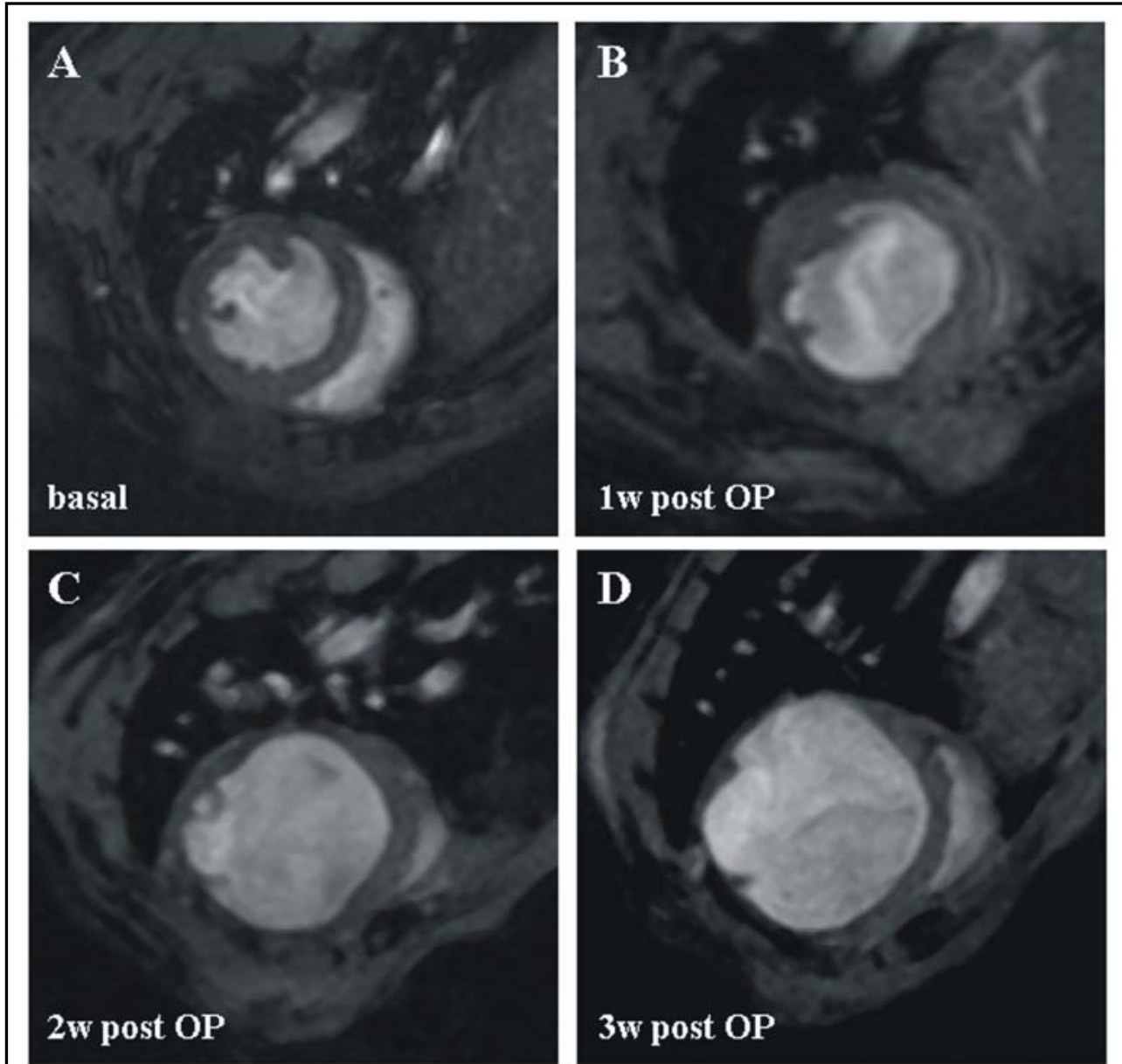

killed by an intracoronary injection of $0.3 \mathrm{ml}$ potassium chloride solution $(1 \mathrm{M})$. The heart is quickly removed and cleaned with a sodium chloride solution. After embedding in Tissue Tec ${ }^{\circledR}$ it is frozen at $-20{ }^{\circ} \mathrm{C}$. The frozen heart is sectioned transversely into 5 slides of approximately $1-2 \mathrm{~mm}$ breadth. Each section is cleaned with sodium chloride solution and incubated in $1 \%$ TTC for 10 minutes. After TTC-staining, viable myocardium stains red and the infarct region appears pale white. The slides are further fixed in $4 \%$ formaldehyde for 2 hours at room temperature. Thereafter, the tissue sections are photographed on both sides using a digital camera mounted atop the stereo microscope. The infarct sizes can be determined by quantitative morphometric planimetry using an image analysis software program (Fig. 8).

In our setting the SEM in infarct size determination was $5.8 \%$ which is comparable to the results of procedure protocols of other groups $[7,11,12]$. Generally, the outcome of infarct healing in mice strongly depends on genetic background [13].

\begin{tabular}{lcl}
\hline Parameter & Abbreviation & Limiting values \\
\hline Heart rate & $\mathrm{HF}$ & $500-600 \mathrm{~min}^{-1}$ \\
Respiratory rate & $\mathrm{RF}$ & $100-120 \mathrm{~min}^{-1}$ \\
End-diastolic volume & $\mathrm{EDV}$ & $50-60 \mu \mathrm{l}$ \\
End-systolic volume & $\mathrm{ESV}$ & $15-20 \mu \mathrm{l}$ \\
Stroke volume & $\mathrm{SV}$ & $35-40 \mu \mathrm{l}$ \\
Ejection fraction & $\mathrm{EF}$ & $65-70 \%$ \\
Cardiac output & $\mathrm{CO}$ & $15-20 \mathrm{ml} / \mathrm{min}$ \\
Myocardial mass $_{M_{\text {myo }} \text { Body weight }}$ & $\mathrm{M}_{\text {myo }}$ & $80-100 \mathrm{mg}$ \\
Myocardial septum thickness $_{\text {Wall thickness }}$ & $\mathrm{rT}$ & $2.5-3.5 \mathrm{mg} / \mathrm{g}$ \\
& $\mathrm{WT}$ & $0.8-1.0 \mathrm{~mm}$ \\
& & $0.8-1.0 \mathrm{~mm}$ \\
\hline
\end{tabular}

Table 2. MRI parameters for analysis of functional outcome after myocardial infarction.

\section{Echocardiography}

Myocardial infarction leads to a reduction of the pump function proportional to the extent of infarction and to a progressive ventricular remodeling which often results

Borst/Ochmann/Schönberger/Jacoby/Stellos/Seizer/Flögel/Lang/ Gawaz 
Fig. 11. Histology and be used to determine particular inflammatory cells and the appearance of further elements in the infarct border zone: (A) HEstain, (B) anti- Mac-3, (C) anti-CD3, (D) anti-PMN, (E) anti-MMP9 immunohistothe area framed in (A). Top: $30 \mathrm{~min}$ occlusion/ $24 \mathrm{~h}$ reperfusion. Bottom: $30 \mathrm{~min}$ occlusion/ $7 \mathrm{~d}$ reperfusion immunohistochemistry can chemistry. (B) - (E) illustrate

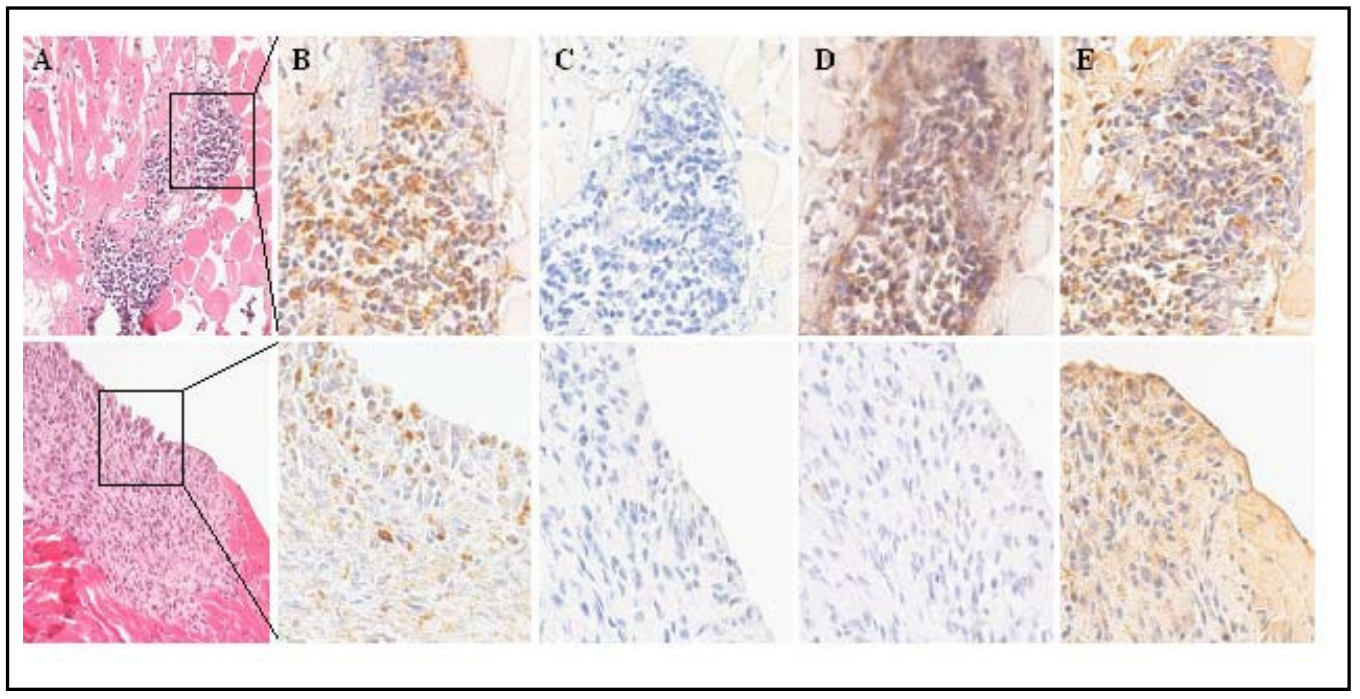

Fig. 12. Representative examples of staining with HE (A), picrosirius red (B) and Masson's trichrome (C) at 24 hours (top), 7 days (middle) and 28 days (bottom) after myocardial ischemia/reperfusion.

\section{A}
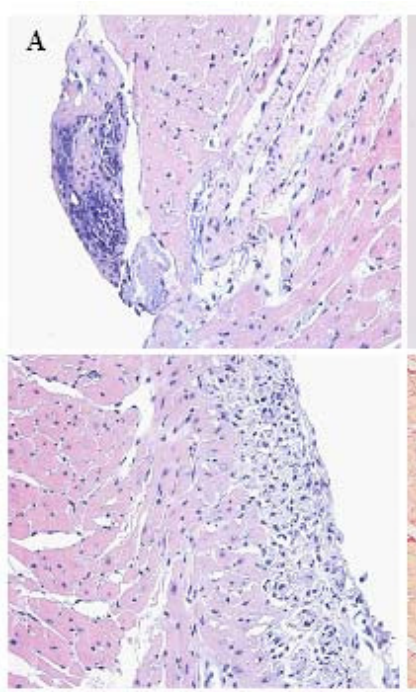

B

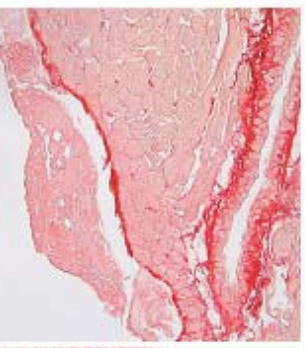

C
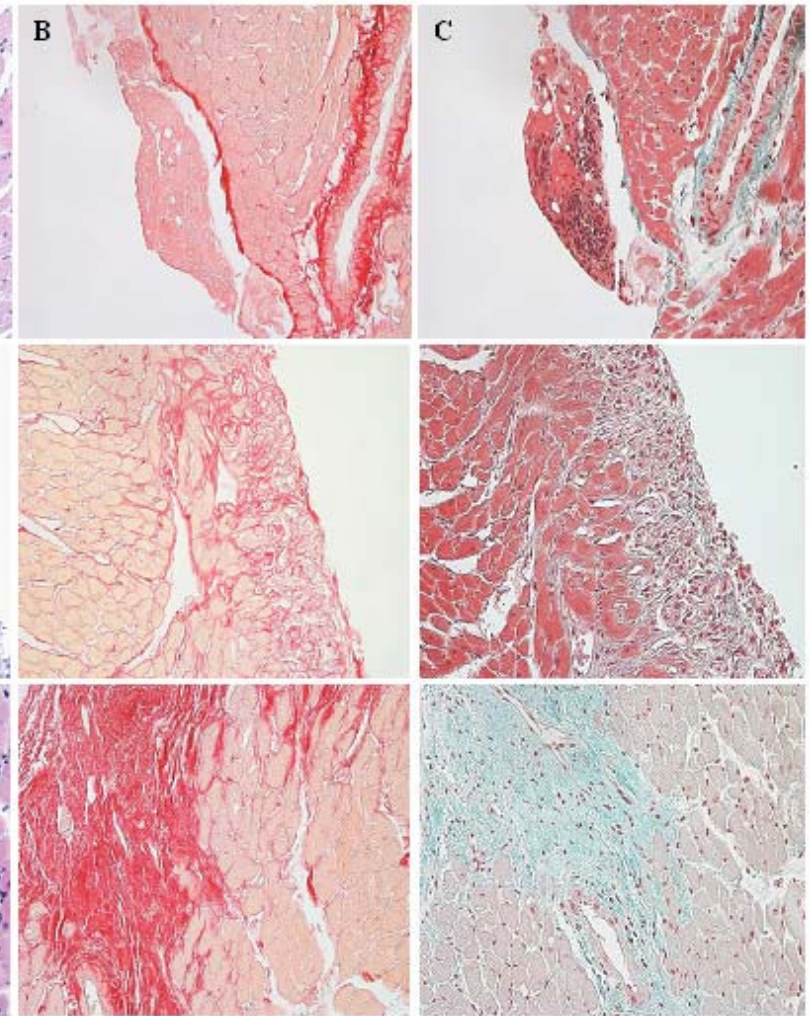

To avoid temperature-related changes in cardiovascular

in ventricular systolic as well as diastolic dysfunction and ultimately contributes to acute or chronic heart failure [1, 14]. Echocardiography is an ideal and non invasive technique to characterize cardiac function serially in one individual. Here, a way how to utilize and evaluate mouse echocardiography after myocardial infarction is described.

Because of the small size of the mouse heart und high heart rates above $400 \mathrm{bpm}$ [15-17] ultrasonic devices with good spatial and temporal resolution should be used. function a temperature control is mandatory [18]. Echocardiography can be carried out on awake or lightly sedated animals. Although anesthesia facilitates immobilization yielding reproducible data, it affects the hemodynamics of the mouse [19]. It causes lower heart rates which are associated with dilatation of the left ventricle. According to a previous study [20], isoflurane and tribromoethanol hardly impaired the cardiac function

Cell Physiol Biochem 2011;28:01-12 
in $\mathrm{C} 57 \mathrm{BL} / 6$, whereas ketamine-midazolame and ketamine-xylazine resulted in numerous effects on echocardiographic parameters. Left ventricular size and function can be assessed using either the M-Mode or 2dimensional images. Indeed, M-mode short axis imaging at the midpapillary level often does not include small infarct sizes. Therefore 2-dimensional echocardiography is more reliable to evaluate the cardiac function after myocardial infarction [21].

Fractional area change (FAC) can be calculated from left ventricle long-axis images at the maximum 2dimensional diameter using the following formula:

$\% \mathrm{FAC}=(\mathrm{EDA}-\mathrm{ESA}) / \mathrm{EDA} \times 100$ [12].

EDA means the end-diastolic (largest) and ESA the end-systolic (smallest) cavity area. These data are determined by manually tracing the endocardial border of the left ventricle (Fig. 9). For each measurement 3 consecutive cardiac cycles should be traced and averaged.

It is also possible to evaluate short axis images at the midpapillary and apical level. The latter can be acquired at the greatest diameter in the lower third of the left ventricle. By tracing the end-diastolic and end-systolic cavity area the FAC can be determined using the formula already mentioned.

\section{Magnetic resonance imaging (MRI)}

Functional and morphological consequences of murine myocardial infarction models can be conveniently monitored by noninvasive magnetic resonance imaging (MRI) [22]. High tissue contrast in the MR images greatly enhances the delineation of cardiac and vascular structures, usually without the need of contrast agents [23, 24]. Mice are lightly anesthetized within the magnet with $1-1.5 \%$ isoflurane and kept at $37^{\circ} \mathrm{C}$. To obtain images at defined time points within the heart cycle, triggering of the imaging sequence to the ECG is indispensable, which is monitored utilizing small electrodes at the fore- and hindpaws. Furthermore, a pressure sensor is used to avoid respiratory motion artifacts by synchronization of the expiratory signal plateau with the pulse sequence. During a complete heart cycle, 15 to 20 images are usually acquired resulting in a temporal resolution of 5-7 ms (assuming a heart rate of $600 \mathrm{~min}^{-1}$ ). A field of view of $3 \times 3$ $\mathrm{cm}^{2}$ and a matrix size of $256 \times 256$ yield a pixel size of $117 \times 117 \mu \mathrm{m}$ (at a slice thickness of $1 \mathrm{~mm}$ ). Temporal and spatial resolution are completely sufficient to routinely determine functional heart parameters even at the high heart rate of the mouse.
Left ventricular (LV) volume reconstruction is performed from contigous short axis slices covering the entire heart (6-10 slices depending on the heart size). For all slices end-diastolic and end-systolic LV endocardial areas are determined which, after multiplication with the slice thickness, provide the partial volumes. End-diastolic (EDV) and end-systolic (ESV) volumes are obtained by summation of all partial volumes associated with the respective heart phases. From the epicardial borders the complete LV volume can be reconstructed in the same way as described for the endocardial volume. Substracting these two volumes provides the pure myocardial volume and, after multiplication with density, the myocardial mass, whereas the myocardial wall thickness can be directly measured. From these measures, a variety of parameters can be calculated. Typical values for healthy, male C57BL/6 mice at the age of 3 months are provided in Table 2. All these parameters can be used to analyze the functional outcome of myocardial infarction in transgenic mouse models. Due to its non-invasive character cardiac MRI is ideally suited for repetitive measurements on the same animal to also follow the course of cardiac remodeling after infarction as a major determinant in the development of heart failure. An impressive example is presented in Fig. 10. Furthermore, changes in the dynamics of LV contraction can directly be assessed using the cine sequence that is aquired for each heart slice.

\section{Gelatin zymography}

MMP-2 and MMP-9 are activated within myocardial tissues after myocardial infarction and are the driving force of left ventricular (LV) remodeling effective by degrading LV matrix components [25, 26]. MMP-2 and MMP-9 activity can be revealed by gelatin zymography e.g. at 24 hours after I/R, as described previously [27]. For this purpose the left ventricle has to be minced into $1-\mathrm{mm}^{3}$ pieces and incubated with PBS containing $0.5 \%$ Triton X-100 (Sigma) and $0.01 \%$ sodium azide in $4{ }^{\circ} \mathrm{C}$ for $18 \mathrm{~h}$. After centrifugation supernatants are harvested and $100 \mu \mathrm{g}$ protein are subjected to electrophoresis.

\section{Histology and immunohistochemistry}

The paraffin technique for preparation of tissue prior to histological examination involves fixation, dehydration,

Borst/Ochmann/Schönberger/Jacoby/Stellos/Seizer/Flögel/Lang/ Gawaz 
clearing, embedding and sectioning. At first the tissue samples are fixated with $4 \%$ formaldehyde. The dehydration occurs by passing the heart slices through graded alcohols in ascending order (70\% ethanol $60 \mathrm{~min}$, $80 \% 60 \mathrm{~min}, 95 \% 60 \mathrm{~min}, 100 \% 2 \times 60 \mathrm{~min})$. Thereby the tissue water is replaced with alcohol. By incubating the tissue samples in xylol, the alcohol is removed. Embedding in paraffin is used to replace the xylol and to form a block. The latter is finally sectioned with a microtome into ca. $5 \mu \mathrm{m}$ thin sections, which are mounted on glass slides. The sections are cleared with xylol and rehydrated in alcohols in ascending order $(100 \% 2 \times 5$ $\min , 95 \% 5 \mathrm{~min}, 70 \% 5 \mathrm{~min}$ ).

Haematoxylin and Eosin (HE) stain can be used to determine the tissue damage and cell recruitment after myocardial infarction. Haematoxylin stains basophilic components like nucleus and endoplasmatic reticulum and appears blue. Eosin binds structures which are eosinophilic, for example proteins and stains pink. The infarcted area can be clearly identified with HE staining (Fig. $11 \mathrm{~A}$ ).

Immunohistochemistry is an appropriate procedure to evaluate cell recruitment in myocardial infarction. According to a previous study [28], inflammation is most intensive at the infarct border zone. Therefore it is advisable to characterize this region in more detail.

By using immunohistochemistry the appearance of particular inflammatory cells which are of central importance for wound healing after mycardial infarction
[29] can be evaluated. It is possible to distinguish between PMN-positive cells which are polymorph nuclear neutrophils [30-32], Mac-3-positive cells which are mouse mononuclear phagocytes [33] and T-lymphocytes which are CD3-positive [34] (Fig. 11 B,C,D).

Furthermore the appearance of particular factors mediating morphological changes in infarcted regions, e.g. MMP-9 [35] (Fig. 11 E), can be determined utilizing the respective staining.

After myocardial infarction, new collagen synthesis as well as deposition starts in the infarcted area already within the first 3 to 4 days postinfarction and achieves its maximum after 1-2 weeks [36]. The interstitial collagen accumulation in the infarcted area can be detected by Masson's trichrome or picrosirius red staining [37] (Fig. 12).

\section{Complications and survival}

All together surgical procedures were performed in 85 mice. Six mice died $(5.1 \%)$. Four of the mice died during surgical manipulation/coronary occlusion and two after the procedure. Causes of death were ventricular tachyarrhythmias and haemorrhage. In two mice it was not possible to stain the myocardium. Further complications not resulting in death of the animals were ascites $(7.7 \%)$, respiratory diseases $(1.7 \%)$, and haematuria $(1.7 \%)$.

\section{References}

1 Patten RD, Aronovitz MJ, Deras-Mejia $>4$ L, Pandian NG, Hanak GG, Smith JJ, Mendelsohn ME, Konstam MA: Ventricular remodeling in a mouse model of myocardial infarction. Am J Physiol 1998;274:H1812-H1820.

$>_{2}$ Duerr GD, Elhafi N, Bostani T, Ellinger $>_{5}$

J, Swieny L, Kolobara E, Welz A, Dewald

$\mathrm{O}$ : Comparison of myocardial remodeling between cryoinfarction and reperfused $\quad 6$ infarction in mice. J Biomed Biotechnol 2011;2011:961298.

-3 Sun Y: Myocardial repair/remodelling following infarction: roles of local factors. Cardiovasc Res 2009;81:482-490.
Bodi V, Sanchis J, Nunez J, Mainar L, Minana G, Benet I, Solano C, Chorro FJ, Llacer A: Uncontrolled immune response in acute myocardial infarction: unraveling the thread. Am Heart J 2008;156:1065-1073.

Cleutjens JP: The role of matrix metalloproteinases in heart disease. Cardiovasc Res 1996;32:816-821. Frangogiannis NG, Smith CW, Entman ML: The inflammatory response in myocardial infarction. Cardiovasc Res 2002;53:31-47.
Michael LH, Entman ML, Hartley CJ, Youker KA, Zhu J, Hall SR, Hawkins HK, Berens K, Ballantyne CM: Myocardial ischemia and reperfusion: a murine model. Am J Physiol 1995;269:H2147H2154.

8 Erhardt W, Haberstroh J, Henke J, Kölle P, Korbel R, Kroker R, Lendel C: Anästhesie \& Analgesie beim Klein- und Heimtier. Schattauer Verlag, Stuttgart 2004, pp 657-658. 
Ahn D, Cheng L, Moon C, Spurgeon H, 19 Lakatta EG, Talan MI: Induction of myocardial infarcts of a predictable size and location by branch pattern probabilityassisted coronary ligation in C57BL/6 mice. Am J Physiol Heart Circ Physiol 2004;286:H1201-H1207.

10 Degabriele NM, Griesenbach U, Sato K, Post MJ, Zhu J, Williams J, Jeffery PK, Geddes DM, Alton EW: Critical appraisal of the mouse model of myocardial infarction. Exp Physiol 2004;89:497-505.

11 Romanic AM, Harrison SM, Bao W, Burns-Kurtis CL, Pickering S, Gu J, Grau E, Mao J, Sathe GM, Ohlstein EH, Yue TL: Myocardial protection from ischemia/reperfusion injury by targeted deletion of matrix metalloproteinase- 9 . Cardiovasc Res 2002;54:549-558.

12 Weig HJ, Bott-Flugel L, Stadele C, Winter K, Schmidt R, Gawaz M, Laugwitz KL, Seyfarth M: Impaired platelet function reduces myocardial infarct size in Galphaq knock-out mice in vivo. J Mol Cell Cardiol 2008;44:143-150.

$>13$ van den Borne SW, van de Schans VA, Strzelecka AE, Vervoort-Peters HT, Lijnen PM, Cleutjens JP, Smits JF, Daemen MJ, Janssen BJ, Blankesteijn WM: Mouse strain determines the outcome of wound healing after myocardial infarction. Cardiovasc Res 2009;84:273282.

14 Cleutjens JP, Creemers EE: Integration of concepts: cardiac extracellular matrix remodeling after myocardial infarction. J Card Fail 2002;8:S344-S348.

15 Desai KH, Sato R, Schauble E, Barsh GS, Kobilka BK, Bernstein D: Cardiovascular indexes in the mouse at rest and with exercise: new tools to study models of cardiac disease. Am J Physiol 1997;272:H1053-H1061.

16 Fewell JG, Osinska H, Klevitsky R, Ng W, Sfyris G, Bahrehmand F, Robbins J: A treadmill exercise regimen for identifying cardiovascular phenotypes in transgenic mice. Am J Physiol 1997;273:H1595-H1605.

17 Uechi M, Asai K, Osaka M, Smith A, Sato N, Wagner TE, Ishikawa Y, Hayakawa H, Vatner DE, Shannon RP, Homcy CJ, Vatner SF: Depressed heart rate variability and arterial baroreflex in conscious transgenic mice with overexpression of cardiac Gsalpha. Circ Res 1998;82:416-423.

18 Johansson C, Gothe S, Forrest D, Vennstrom B, Thoren P: Cardiovascular phenotype and temperature control in mice lacking thyroid hormone receptorbeta or both alpha1 and beta. Am J Physiol 1999;276:H2006-H2012.
Yang XP, Liu YH, Rhaleb NE, Kurihara $\mathrm{N}, \quad$ Kim HE, Carretero OA: Echocardiographic assessment of cardiac function in conscious and anesthetized mice. Am J Physiol 1999;277:H1967H1974.

20 Roth DM, Swaney JS, Dalton ND, Gilpin EA, Ross J Jr: Impact of anesthesia on cardiac function during echocardiography in mice. Am J Physiol Heart Circ Physiol 2002;282:H2134-H2140.

21 Suehiro K, Takuma S, Shimizu J, Hozumi T, Yano H, Cardinale C, DiTullio MR, Wang J, Smith CR, Burkhoff D, Homma $\mathrm{S}$ : Assessment of left ventricular systolic function using contrast two-dimensional echocardiography with a high-frequency transducer in the awake murine model of myocardial infarction. Jpn Circ J 2001;65:979-983

22 Flogel U, Ding Z, Hardung H, Jander S, Reichmann G, Jacoby C, Schubert R, Schrader J: In vivo monitoring of inflammation after cardiac and cerebral ischemia by fluorine magnetic resonance imaging. Circulation 2008;118:140-148.

23 Flogel U, Laussmann T, Godecke A, Abanador N, Schafers M, Fingas CD Metzger S, Levkau B, Jacoby C, Schrader $\mathrm{J}$ : Lack of myoglobin causes a switch in cardiac substrate selection. Circ Res 2005;96:e68-e75.

24 Flogel U, Jacoby C, Godecke A, Schrader $\mathrm{J}$ : In vivo $2 \mathrm{D}$ mapping of impaired murine cardiac energetics in NO-induced heart failure. Magn Reson Med 2007;57:50 58 .

Creemers EE, Cleutjens JP, Smits JF, Daemen MJ: Matrix metalloproteinase inhibition after myocardial infarction: new approach to prevent heart failure? Circ Res 2001;89:201-210.

26 Matsumura S, Iwanaga S, Mochizuki S, Okamoto H, Ogawa S, Okada Y: Targeted deletion or pharmacological inhibition of MMP-2 prevents cardiac rupture after myocardial infarction in mice. J Clin Invest 2005;115:599-609.

27 Seizer P, Ochmann C, Schonberger T, Zach S, Rose M, Borst O, Klingel K, Kandolf R, Macdonald HR, Nowak RA, Engelhardt S, Lang F, Gawaz M, May AE: Disrupting the EMMPRIN (CD147)Cyclophilin A Interaction Reduces Infarct Size and Preserves Systolic Function After Myocardial Ischemia and Reperfusion. Arterioscler Thromb Vasc Biol 2011;31:1377-1386. Perrard JL, Michael LH, Ballantyne CM, Smith CW, Entman ML: Molecular evidence for a border zone vulnerable to inflammatory reperfusion injury. Trans Assoc Am Physicians 1993;106:145154.

29 Frantz S, Bauersachs J, Ertl G: Post-infarct remodelling: contribution of wound healing and inflammation. Cardiovasc Res 2009;81:474-481

30 Lubberts E, Joosten LA, van Den BL, Helsen MM, Bakker AC, van Meurs JB, Graham FL, Richards CD, van Den Berg WB: Adenoviral vector-mediated overexpression of IL-4 in the knee joint of mice with collagen-induced arthritis prevents cartilage destruction. J Immunol 1999; $163: 4546-4556$

31 Tacchini-Cottier F, Zweifel C, Belkaid Y, Mukankundiye C, Vasei M, Launois P, Milon G, Louis JA: An immunomodulatory function for neutrophils during the induction of a $\mathrm{CD} 4+\mathrm{Th} 2$ response in BALB/c mice infected with Leishmania major. J Immunol 2000;165:2628-2636.

32 Van Lent PL, Blom A, Holthuysen AE, Jacobs CW, Van De Putte LB, van Den Berg WB: Monocytes/macrophages rather than PMN are involved in early cartilage degradation in cationic immune complex arthritis in mice. J Leukoc Biol 1997;61:267-278.

33 Flotte TJ, Springer TA, Thorbecke GJ: Dendritic cell and macrophage staining by monoclonal antibodies in tissue sections and epidermal sheets. Am J Pathol 1983;111:112-124.

34 Yilmaz A, Klingel K, Kandolf R, Sechtem $\mathrm{U}$ : Imaging in inflammatory heart disease: from the past to current clinical practice. Hellenic J Cardiol 2009;50:449460.

35 Vallbo C, Damber JE: Thrombospondins, metallo proteases and thrombospondin receptors messenger RNA and protein expression in different tumour sublines of the Dunning prostate cancer model. Acta Oncol 2005;44:293-298.

Cleutjens JP, Verluyten MJ, Smiths JF, Daemen MJ: Collagen remodeling after myocardial infarction in the rat heart. Am J Pathol 1995;147:325-338.

37 Ducharme A, Frantz S, Aikawa M, Rabkin E, Lindsey M, Rohde LE, Schoen FJ, Kelly RA, Werb Z, Libby P, Lee RT: Targeted deletion of matrix metalloproteinase-9 attenuates left ventricular enlargement and collagen accumulation after experimental myocardial infarction. J Clin Invest 2000;106:5562. 